Sādhanā Vol. 38, Part 5, October 2013, pp. 775-794. (C) Indian Academy of Sciences

\title{
Indian nuclear power programme - Past, present and future
}

\author{
S A BHARDWAJ \\ Nuclear Power Corporation of India Limited, Anushaktinagar, \\ Mumbai 400 094, India \\ e-mail: sabhardwaj@gmail.com; sabhardwaj@npcil.co.in
}

\begin{abstract}
The country is facing energy shortages at present for the connected load. A large population even now does not have access to electricity. As the economy expands and the population increases, the country will need to generate even more power to meet the growing demand. Resources of energy are experiencing constraints to meet the current demand. The generating capacities in the country are underperforming at present because of fuel supply constraint. Analysis in the Energy Policy document hints that conventional fuel resources will begin to exhaust by middle of the century. All these indicate that for India to be able to meet its growing demand, nuclear and solar power could provide energy security in the long term. The first stage of commercially successful nuclear power programme has indicated that country has command on the technology through its own R\&D base built since the beginning of establishing Department of Atomic Energy. On this strength it could withstand the technology denial regime for years. The second stage (Fast Breeder Reactor) programme has been initiated. Given the scientific and technological capability demonstrated so far, the technology required for optimizing the second stage programme and launching the third stage programme can be developed to assure long term energy security at the desired capacity.
\end{abstract}

Keywords. Three stage nuclear power programme; PHWRs; FBTR; AHWR; thorium.

\section{Introduction}

Energy availability is vital for human development and is the prime mover of economic growth. As population increases and economic growth continues, the demand for energy will further rise. Since agriculture, services and industrial sectors are all driven by power, there is an everincreasing need to generate more power.

One important mission of the Department of Atomic Energy is to harness nuclear energy as a safe, environmentally benign and economically viable source of electric power to meet the everincreasing energy needs of the country. This is to be achieved through the concerted effort of operating existing Nuclear Power Plants (NPPs) in an efficient manner, implementing new power projects and developing/adopting new technologies for nuclear power production and fuel cycle processes for future deployment. 
India is the seventh largest country in the world with an area of 3.3 million sq. km. and population of about 1.2 billion (the second most populous country after China). As of today, a significant segment of this population does not have access to electricity and other clean fuels, and those who have electricity available to them face shortages of it regularly. According to the Central Electricity Authority estimates, the peaking shortage prevails in various regions of the country from $1.3 \%$ up to 26.1\% (Load Generation Balance Report 2013-14).

As the economy grows and more people are provided access to electricity, this gap between demand and supply will further increase. The population of India is expected to increase to about 1.5 billion by 2050 . Concurrently, India is also economically growing in terms of GDP rapidly at a rate of about $6-8 \%$ a year. Sustaining the economic growth at current rate is essential to meet the country's primary objectives of poverty alleviation and improving the quality of life. For its growing population, increased attention needs to be paid to provide energy, especially electricity supply.

It has been reported that a correlation exists between energy/electricity consumption and the indices of quality of life of a country's population like the human development index (HDI) (Leung 2005; Human Development Reports 2007). The Human Development Index is a way of measuring development by combining indicators of life expectancy, educational attainment and income into a composite human development index, the HDI of a country. Correlation between Human Development and Per Capita Electricity Consumption (figure 1) indicates that 4,000 $\mathrm{kWh}$ per person per year is the dividing line between developed and developing countries. In comparison, India at present has about $700 \mathrm{kWh}$ per capita per year availability of electricity. In order to improve the HDI, India needs to augment its installed capacity base at a faster pace.

Alleviation of the poverty and enhancing the standard of living of the large population are the objectives of national policies and programmes. All key drivers for sustaining the growth, particularly energy/electricity, have acquired a focused attention of planners, policy makers and the Government.

The present resources in the country's energy mix being used for producing electricity are illustrated in figure 2 (Energy Statistics Report 2012). Coal is the main resource being used at present and coal-fired plants will continue to be the primary source of electricity production in the country for quite some time to come, The Integrated Energy Policy (Integrated Energy Policy 2006) indicates that at a growth rate of 5\% in domestic production, currently extractable

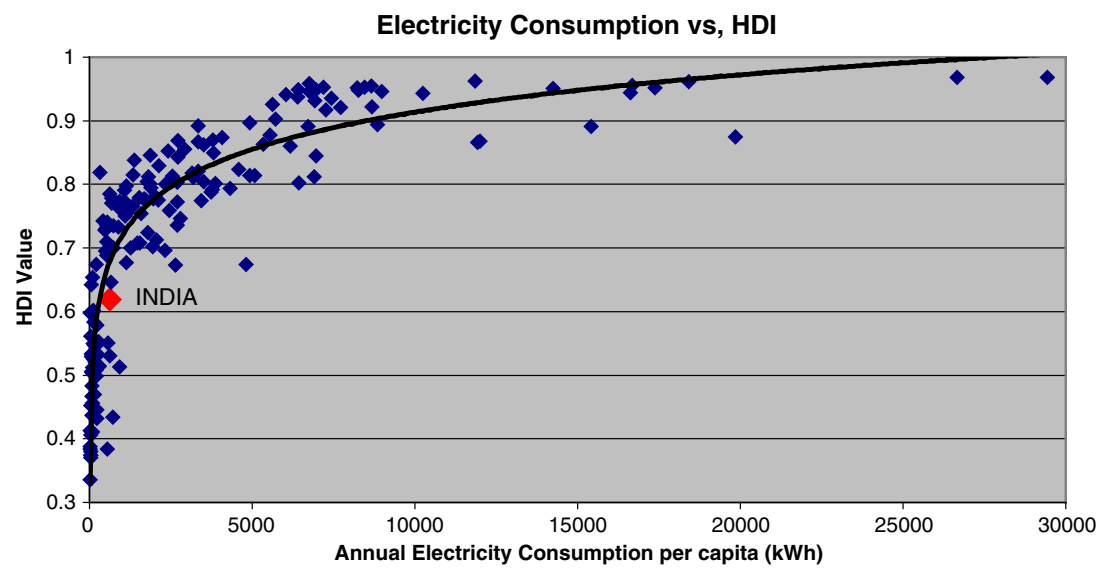

Figure 1. Electricity consumption versus Human Development Index. 


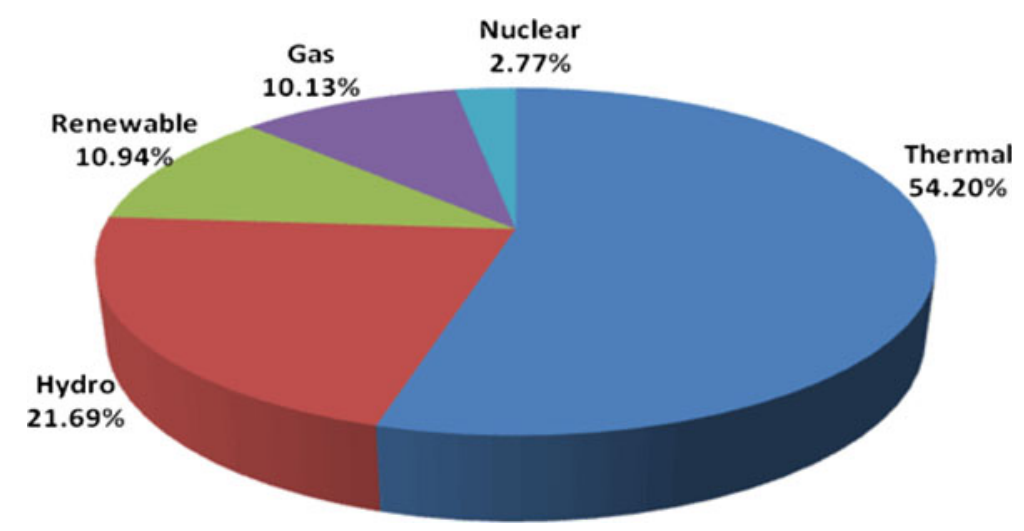

Figure 2. Break-up of installed power capacity (MW) in India as on January 31, 2011.

coal resources will be exhausted in about 45 years. Vigorous efforts are required to survey and to identify additional potential coal bearing areas. Nearly 80 per cent of the oil is imported in the country, which is an area of concern for the Government with regard to energy security in the near future. Addition of hydro potential has the limitation which is determined by rainfall and topography of the location of water sources. Other renewable energy sources like wind have similar limitations of growth and energy supply. In comparison, Nuclear energy theoretically offers India the most potent means for long term energy security. Renewable energy source like solar energy also holds a promise as a possible inexhaustible energy source for a tropical country like India. Use of extensive solar energy may call for change in pattern of energy consumption and urbanization.

India's nuclear energy resource profile, shown in table 1 indicates that nuclear power offers the most potent means for long-term energy security. Currently, the nuclear energy share in electricity generation is about $3 \%$. The nuclear share in total primary energy mix is expected to grow, as the installed nuclear power capacity grows. The Integrated Energy Policy of India estimates the share of nuclear power in the total primary energy mix to be between 4.0 and $6.4 \%$ in various scenarios in the year 2031-32 (Integrated Energy Policy 2006).

Thus, Nuclear energy, in view of its huge potential and techno-commercial viability, will play an increasingly important role in the future. The rate of growth of nuclear share at the primary level is expected to be rapid as conventional fossil fuel sources, particularly coal, approach exhaustion, or their extraction tends to become uneconomical. Further, with other energy related

Table 1. India's nuclear energy resource base.

\begin{tabular}{|c|c|c|c|c|}
\hline & \multirow[b]{2}{*}{ Amount } & \multicolumn{2}{|c|}{ Thermal energy } & \multirow{2}{*}{$\frac{\text { Electricity potential }}{\text { GWe-yr }}$} \\
\hline & & TWh & GW-yr & \\
\hline Uranium-Metal & $61,000-\mathrm{T}$ & & & \\
\hline In PHWR & & 7,992 & 913 & 328 \\
\hline In Fast Breeders & & $1,027,616$ & 117,308 & 42,200 \\
\hline Thorium-Metal & $2,25,000-\mathrm{T}$ & & & \\
\hline In Breeders & & $3,783,886$ & 431,950 & 150,000 \\
\hline
\end{tabular}

Source: Integrated Energy Policy (2006) 
applications of nuclear energy viz. production of hydrogen, desalination of water, etc. are expected to grow the nuclear share at the primary level.

\section{Merits of nuclear power}

Nuclear power is an intense source of energy and the transport infrastructure needed for nuclear fuel is very small. 10,000 MWe nuclear power capacity needs only about 300-350 tons of enriched fuel per annum, as against 35-50 million tons of coal needed for a coal fired thermal power station of the same capacity requiring about a shipload or 20 trainloads per day to transport the coal. The pressure on rail, port and other infrastructure will be immense when large thermal capacity is added, apart from emissions arising out of transporting such large quantities of coal. The land needed for setting up a nuclear power station is also less when compared to thermal coal-fired power stations and hydroelectric stations which involve large submergence of land.

Climate change arising out of Green House Gas Emissions is among the most important challenges facing the world today. The effects of climate change are expected to be catastrophic, with crop losses, sea-level rise, extreme weather events and other losses predicted by various models. In terms of economic losses, the Stern Report (2007) had predicted losses to the tune of $20 \%$ of the global GDP on account of climate change by 2050, if action is not initiated immediately. Although India's per capita emissions are among the lowest in the world, in absolute terms, the emissions are sizeable (at $4.8 \%$ of global emissions) on account of the large population. Emissions in future are projected to grow rapidly in India and China. The power sector contributes significantly to Green House Gas emissions, estimates of which vary from 40 to $50 \%$ of total emissions of Green House Gases. De-carbonisation of the energy/power sector is one of the key recommendations made by various reports like the recent Intergovernmental Panel on Climate Change (IPCC) report in this regard (Pachauri and Reisinger 2007).

Nuclear power is environmentally benign and the life cycle Greenhouse Gas emissions of nuclear power are comparable to that of wind and solar photovoltaic power. The life cycle emissions (from mining of ore to waste disposal) of nuclear power are very low, between 2.5 and $5.7 \mathrm{gCeq} / \mathrm{kWh}$ (grams of Carbon Equivalent per unit of electricity) as against 206 to $357 \mathrm{gCeq} / \mathrm{kWh}$ in case for coal and 106 to $188 \mathrm{gCeq} / \mathrm{kWh}$ for gas technologies (IAEA 2000).

The base line $\mathrm{CO}_{2}$ emissions in India from the predominant technology, coal, are about $1 \mathrm{~kg} / \mathrm{kWh}$. Thus every unit of nuclear power generated saves $1 \mathrm{~kg}$ of $\mathrm{CO}_{2}$ emissions. Thus nuclear power in India, which has generated about 284 billion units so far, has saved the earth of 284 million tones of $\mathrm{CO}_{2}$. Every $1000 \mathrm{MWe}$ nuclear power station to be set-up in future will save about 7 million tons of $\mathrm{CO}_{2}$ emissions every year. Nuclear power can be a major facilitator in de-carbonising the energy sector and the same has been well recognized in the country's Integrated Energy Policy.

\section{Historical perspective of nuclear power in India}

\subsection{Genesis of nuclear power in India}

Unlike the advanced countries where nuclear power came about as a spin-off from the development of the strategic programme and related military research, in India, nuclear energy development began with the objectives of improving the quality of life of the people and selfreliance in meeting their energy needs. The origin of the atomic energy programme in India 
(Saga of Atomic Energy in India 2005) can be traced unambiguously to a remarkably bold initiative taken by Homi Jehangir Bhabha. In 1944, he addressed a letter to Sir Dorabji Tata Trust, outlining the urgent need to initiate nuclear research in India to keep abreast with international developments. He proposed setting up of a rigorous school of research in fundamental physics for this purpose. Bhabha prophesied that a completely self-reliant power programme would come about within two decades. Sir Dorabji Tata Trust granted an initial financial approval for settingup the Tata Institute of Fundamental Research (TIFR), Bombay (presently Mumbai), jointly with the Bombay Government. Between 1945 and 1954, research work at TIFR, in the fields of nuclear physics, cosmic rays and electronic instrumentation was taken up.

On 10th August 1948, the Government of India constituted the Atomic Energy Commission (AEC), under the Atomic Energy Act to establish the atomic energy programme. One of the first tasks of the Commission was to explore the availability of raw material resources within the country. Based on initial explorations by Atomic Minerals Division, it became clear that the country had limited uranium resources but was endowed with one of the largest thorium reserves in the world. This led Bhabha to conceive a three-stage nuclear power programme for efficient exploitation of available resources, unique to India. The sequential three-stage programme was based on a closed fuel cycle, where the spent fuel of one stage is reprocessed to recover fuel for the next stage. The closed fuel cycle thus multiplies manifold the energy potential of the fuel and greatly reduces the quantity of waste generated.

\subsection{Department of Atomic Energy}

On 3rd August 1954, the Department of Atomic Energy (DAE) was established. Immediate effort was to develop key elements of infrastructure for a nuclear power programme. All scientists and engineers engaged in the fields of reactor design and development, instrumentation, metallurgy and material science, etc. were transferred with their respective programmes from the Tata Institute of Fundamental Research (TIFR) to Atomic Energy Establishment, Trombay (AEET).

\subsection{Infrastructure creation and initial $R \& D$ goals for power programme}

Bhabha with regard to Human Resource development had said "When nuclear energy has been successfully applied for power production in, say, a couple of decades from now, India will not have to look abroad for its experts but will find them ready at hand." A regular Training School started functioning in 1957 and the programme has evolved as a primary resource for providing training in nuclear science and technology to engineers and scientists from various disciplines (Grover and Puri 2013). The other areas listed for development by DAE included prospecting for and processing of uranium, construction of plants to produce heavy water and beryllium, erecting facilities such as a uranium enrichment plant, atomic power plants, breeder reactors and a plutonium extraction plant. In May 1956, a decision was taken to set-up a pilot plant at AEET for making pure uranium metal and for fabricating it into fuel elements for research reactors planned at Trombay. It may also be mentioned that nuclear safety was given a due recognition from initial period-a Radiation Hazard Control Section was in existence from early stages (Regulaton Framework 2008; Parthasarthy 2010), which has evolved to a network of radiation protection, health physics, nuclear safety and regulatory organisations as on today. Towards developing science and technology and understanding of nuclear reactor technology, several research reactors were systematically designed and built during different stages of the programme. The first of these reactors was a swimming pool type of reactor, "APSARA". The basic design for this 
reactor was frozen in July 1955 and Indian scientists and engineers completed the construction in just over a year. With APSARA, India became the first Asian country outside the erstwhile Soviet Union, to have designed and built its own nuclear reactor.

The next crucial step involved the planning of larger reactors having much higher neutron flux and power materialized in 1960 with the building of CIRUS, a high power (40 $\mathrm{MW}_{\text {th }}$ ) research reactor. This reactor was built in collaboration with Canada. CIRUS and APSARA became centres of excellence in nuclear education. Experiments carried out at APSARA and CIRUS have provided the necessary confidence and expertise for design and safe operation of many nuclear reactors in the country. In early 1961, a zero energy critical facility named ZERLINA was built, for studying various geometrical aspects (lattice parameters) of a reactor fuelled with natural uranium and moderated with heavy water. In the early seventies, a need was felt for a research reactor having even larger neutron flux and irradiation volumes than CIRUS, for meeting the growing requirements for radioisotopes and research. This culminated in building of a totally indigenous $100 \mathrm{MW}_{\text {th }}$ research reactor. It attained criticality in August 1985 and was named DHRUVA.

It may be recalled that the three-stage programme calls for building of plutonium based reactors in the second stage. Reprocessing of spent fuel from the first stage uranium fuelled reactors is required to make available the required Plutonium. The first fuel reprocessing facility of this type was inaugurated at BARC in 1965. Therefore; the next logical step was to build a critical facility, which used plutonium as fuel. Such a test reactor was built in 1972 and was named PURNIMA (Plutonium Reactor for Neutron Investigations in Multiplying Assemblies). This reactor was intended for studying the behaviour of plutonium fuel in a pulsed fast reactor (PFR). Following this, a critical facility called PURNIMA-2 was designed, with a solution containing 400 gms of uranyl nitrate serving as the fuel for this facility. Apart from thermal power reactors, towards, gaining firsthand experience in the fast reactor technology, it was decided to construct a Fast Breeder Test Reactor (FBTR) (Chetal and Chellapandi 2013) at Reactor Research Centre, Kalpakkam (later renamed as Indira Gandhi Centre for Atomic Research). FBTR was commissioned in 1985, with indigenous plutonium-uranium mixed carbide fuel, providing valuable design and operational experience. As a part of studies with ${ }_{233} \mathrm{U}$ fuel, a $30 \mathrm{~kW}$ pool type research reactor, KAMINI (Kalpakkam MINI), was designed and built. Prior to this, a mock up of the core of this reactor, was built and made critical in April 1992. It was given the name PURNIMA-3. KAMINI was made operational in 1996. This reactor is being extensively used as a neutron source for research applications such as neutron radiography of irradiated nuclear fuel.

The development of most of these reactor systems is an integrated result of detailed understanding of science and technology involved and provided useful experience for power reactor technology. Capability in all aspects of $\mathrm{R} \& \mathrm{D}$, reactor physics design, engineering design and safety analysis was demonstrated in the country. This included in-house development of nuclear material processing and fabrication required for key nuclear reactor components (Suri 2013). Critical mechanical equipment, fuel, nuclear grade reactor internal materials, control and instrumentation, etc., used in these reactors were supplied from within as a result of sustained all around development work carried out by R\&D facilities of DAE and other R\&D organisations.

In short, self-reliance through R\&D has been the hallmark of the Indian nuclear power programme right from the inception of DAE. Thorough understanding and capability building in primary areas of nuclear technology was taken upfront before nuclear power plants were taken up for construction. India has become one of the few countries in the world that has acquired expertise in the entire range of nuclear fuel cycle activities. As these activities were of special nature and did not form a part of the general industrial domain of the country, DAE established facilities for carrying them out in a proper phased manner. Establishment of industrial infrastructure 
for nuclear fuel cycle activities was backed by the strong R\&D base of DAE. This infrastructure building activity was started well before launching the nuclear power programme. In addition, significant efforts were put in by DAE to develop indigenous manufacturing capability to make various equipment/components conforming to stringent quality standards of the nuclear power industry. In retrospect, this policy of self-reliance has paid rich dividends in the form of negating the effects of restrictive trade barriers and technology denials, in this field. This approach has also resulted in technological spin-offs for the Indian industry.

\subsection{Organisation structure}

As a result of work taken up in all related fronts the Department of Atomic Energy has been structurally evolving as required (http://dae.nic.in/). Research and Development and prototype fabrication experiences as above were translated into industrial activities of the Department. For example, the Uranium Corporation of India Limited (UCIL) was registered as a Public Sector company in 1967, Nuclear Fuel Complex (NFC) was established in Hyderabad in 1968 to produce nuclear fuels in large quantities and zirconium based alloy structures and tubular materials of different special materials for reactor use. To cater to the large requirements of heavy water for the PHWR reactors, a heavy water group was established in 1969. At present Heavy Water Board is responsible for design, construction and operation of plants for supply of heavy water to PHWRs. Heavy Water Board also provides its expertise for supply of boron carbide, for PFBR and certain other solvents and chemicals for use by DAE units. Electronics Corporation of India Limited (ECIL) at Hyderabad for the manufacture of not only nuclear electronic instrumentation, but also a variety of electronic components and equipment which had been designed and developed at Trombay. ECIL started functioning in April 1967 and has evolved into a major supplier of nuclear electronic control systems and electronic hardware to other strategic sectors and for societal applications of high value to the Nation.

The Nuclear Power programme is being integrated and executed by two organizations namely Nuclear Power Corporation of India Ltd. (NPCIL) for thermal reactors of the first stage programme of DAE and Bharatiya Nabhikiya Vidyut Nigam Ltd. (BHAVINI) for Fast Breeder Reactors of the second stage programme of DAE. These are supported for R\&D primarily by Bhabha Atomic Research Centre (BARC) and Indira Gandhi Centre for Atomic Research (IGCAR). Other R\&D centres like Raja Ramanna Centre for Advanced Technology support certain special development activities related to laser based tools, etc. Advanced Fuel Fabrication Facility of BARC participates in fuel fabrication for Fast Reactors. Fuel reprocessing, waste management, radiation protection services are supported by BARC.

DAE also supports eight institutes of international repute engaged in research in basic sciences, astronomy, astrophysics, cancer research and education. It has under its aegis two boards for promoting and funding extra-mural research in nuclear and allied fields, mathematics and a national institute (deemed university).

\section{India's three-stage programme}

The adoption of the unique sequential three-stage nuclear power programme and associated technologies is based on the optimum utilization of the indigenous nuclear resource profile of modest Uranium and abundant Thorium in the country, the potential of which has already been given in the foregoing sections. India's three-stage nuclear power programme is shown pictorially in 
figure 3. The three-stage power programme of DAE has been planned based on a closed fuel cycle concept, requiring reprocessing of spent fuel from every reactor. The objective is to judiciously utilize mined uranium and thorium resources of the country to a maximum extent. Uranium has just $0.7 \%$ fissionable ${ }_{235} \mathrm{U}$ isotope while ${ }_{238} \mathrm{U}$, the balance dominant isotope of uranium is a fertile material. It needs to be converted to fissile ${ }_{239} \mathrm{Pu}$ for further use. The process of this conversion does take place in a nuclear reactor where uranium fuel is used. Uranium's fissile isotope, ${ }_{235} \mathrm{U}$ present as a very small fraction in uranium, produces excess neutrons over and above those required for maintaining a steady fission chain reaction. Some of these excess neutrons invariably get absorbed in the major isotope ${ }_{238} \mathrm{U}$ and result in production of ${ }_{23} \mathrm{Pu}$. By suitable reactor physics design of a nuclear reactor the production of $\mathrm{Pu}$ can be optimized. Thus the spent fuel from thermal reactors contains a small quantity of ${ }_{239} \mathrm{Pu}$, along with residual uranium (predominantly ${ }_{238} \mathrm{U}$ ). The spent fuel can be reprocessed chemically to separate plutonium, residual uranium and the fission products, etc. Plutonium 239 is a fissile material and when used in Fast Reactors, where neutron energies are kept high (by not slowing them through use of a moderator as in thermal reactors), is more efficient in producing excess neutrons during fission chain reaction. These excess neutrons are used by proper reactor physics design to convert ${ }_{238} \mathrm{U}$ into additional Plutonium. By suitable choice of fuel type and reactor configurations such Fast Reactors can produce a little more $\mathrm{Pu}$ than they consume, hence breed more fuel from spent Uranium obtained from reprocessing, thus the name 'Breeder' Reactors. Similarly, thorium is a fertile material and has to be converted to a fissile material, viz. ${ }_{233} \mathrm{U}$ to be used for power production. A closed fuel cycle approach as mentioned above, involving reprocessing of spent fuel to separate the useful fissile and fertile isotopes from spent fuel and reusing them in nuclear reactors has been adopted as a guiding principle for our nuclear energy programme to ensure long term energy security for the country. The second stage, comprising of Fast Breeder Reactors (FBRs) are fuelled by fuels based on Plutonium mixed with reprocessed Uranium recovered by reprocessing of the first stage spent fuel. In FBRs, Plutonium 239 undergoes fission producing energy, and at the same time, producing Plutonium 239 by transmutation of Uranium 238 . Over a period of time,

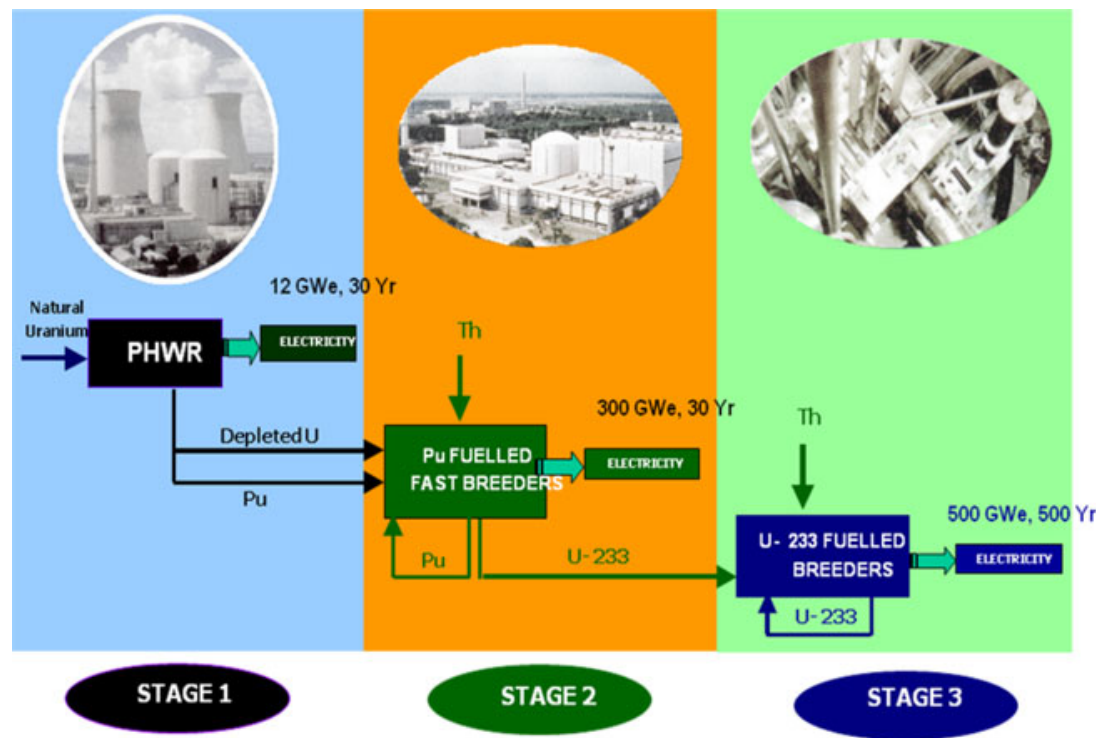

Figure 3. India's three-stage nuclear power programme. 
growing Plutonium inventory can multiply the number of FBRs. The process of increasing the nuclear power capacity can thus be achieved to a desired level in the country through Plutoniumbased FBRs. Thorium 232 is not fissile and has to be converted to Uranium 233 by transmutation in a reactor for use as a fissile material. In the second stage, once sufficient nuclear power capacity is built through Plutonium-based FBRs, Thorium 232 will be introduced as a blanket material to be converted to Uranium 233 . The third stage of the programme will be using a Thorium $232-$ Uranium $_{233}$ fuel cycle in the reactors. Direct use of Thorium 232 as a fuel will thus be in the third stage reactors. Thorium $232-$ Uranium $_{233}$ fuel cycle does not permit attractive breeding characteristics like that of $\mathrm{Pu}-\mathrm{U}$ cycle but would facilitate the nuclear power capacity built during second stage of the programme to be sustained for as long as Thorium, which is quite large in the country, is available.

\section{First stage}

First stage of Indian Nuclear Power Programme comprises of thermal reactors fuelled by uranium. The work on the first nuclear power project in the country was commenced at Tarapur, Maharashtra (TAPS-1 \& 2) in 1964 and the reactor type chosen was Boiling Water Reactor (BWR). India figured on the nuclear map of the world in 1969, when these two Boiling Water Reactors (BWRs), TAPS-1 and TAPS-2, were commissioned at Tarapur Atomic Power station (TAPS). TAPS-1\&2 were turnkey projects from M/s General Electric (GE), USA, which were handed over on completion to DAE for operation and maintenance. The main objectives of setting-up these units were to prove techno-economic viability of nuclear power, to obtain experience in operation and maintenance of nuclear power plants and to demonstrate technical viability of operating the nuclear power stations in the Indian regional grid system. All the components of the power plant and nuclear fuel were imported and the role of Indian industries was limited to certain construction, erection and service contracts.

Pressurised Heavy Water Reactor (PHWR) technology (Bajaj and Gore 2006) was however chosen for the first stage of the three stage nuclear power programme, as these are efficient producers of plutonium required for the second stage and the reactor components could be considered to be produced in India to a great extent with the participation of the then capability of Indian Industry. As part of this main thrust of developing PHWR designs, Rajasthan Atomic Power Station (RAPS) consisting of two units, RAPS-1 and RAPS-2, was taken up as a joint Indo-Canadian venture in the late sixties, at Rawatbhata, Rajasthan. Canada furnished nuclear designs and also supplied all the main equipment for the first unit. India retained responsibility for construction, installation and commissioning activities. For the second unit (RAPS-2), manufacture of reactor components was taken up in India and the import content was reduced considerably. Canada withdrew support for the plant in 1974 due to the Pokhran tests and Indian engineers carried out remainder of the design, construction and commissioning work of the RAPS second unit. The period following 1974 demonstrated the strength of scientific and technical capability created in the country by DAE. The TAPS units and RAPS unit 1 continued to operate, with day-to-day reactor physics calculations, fuel fabrication and supply, and other operation and maintenance engineering support by DAE units and by Indian industry.

From the third nuclear power plant, Madras Atomic Power Station (MAPS) consisting of two units, MAPS-1 and MAPS-2, at Kalpakkam, Tamilnadu, India had started carrying out all facets of the work on its own. A notable number of design changes were incorporated at MAPS. Improved reactor designs were developed to keep abreast with evolutionary changes 
taking place worldwide and to meet new safety criteria. Since there was a requirement to establish PHWRs at various sites in different electricity regions of the country, it was also necessary to evolve designs that met site-specific environmental and seismic criteria. In order to commence construction of PHWRs at a number of sites more or less simultaneously, it became necessary to evolve a standardized design. Improvements were also incorporated to enhance reliability of operation and productivity, reduce costs and attain better capacity factors. The first two units of PHWR using indigenously developed standardized 220 MWe plant design were set-up at the Narora Atomic Power Station (NAPS). Subsequently, three more twin unit atomic power stations of the standardized and optimised design, with capacity of $2 \times 220 \mathrm{MWe}$ each, were built and commissioned at Kakrapar, Kaiga and Rawatbhata using indigenous technology. Successful commissioning and subsequent operation of these stations have clearly demonstrated that India has mastered the technology involved and is fully capable of utilizing the same in the commercial domain. This also established nuclear power as a safe, environmentally benign and economically viable source of power that offers energy security for the country.

In order to realize economies of scale, design for 540 MWe PHWR was developed and construction of two such units was taken up at Tarapur. The construction of these units in a record time in line with international bench mark and later smooth commissioning and successful operation confirms maturity achieved in design, development and construction and commissioning of nuclear power plants. In order to further optimize the cost of electricity production through economy of scale, NPCIL has modified the 540 MWe PHWR design to that of 700 MWe capacity (Bhardwaj 2006). Four units of this design are being constructed at present. Future PHWR programme will primarily use this design.

To accelerate growth of nuclear power capacity using uranium-based thermal reactors, $2 \times$ 1000 MWe VVER reactors are being commissioned at Kudankulam with the cooperation of the Russian Federation. Similarly it is planned to install large size Light Water Reactors (LWRs) through international cooperation which is now available. These plants will be in addition to the indigenous PHWR programme of first stage.

\subsection{Achievements in nuclear power plant operation}

Nuclear Power plants in operation have registered high availability factor, safety performance and longest continuous operation comparable to international standards. The performance of the operating plants is depicted in the figure 4.

\subsection{Project construction performance}

NPCIL has engineered the methodology and strategies for Nuclear Power Projects execution with the growing capability of Indian industry and has been achieving reduction in gestation period. The construction and commissioning of TAPS $3 \& 4$ and Kaiga- 3 in five years and well with in the estimated cost further endorses this. Figure 5 indicates that the gestation time achieved in construction of nuclear power reactors in India is comparable to international standards.

\subsection{Safety in Indian nuclear power plants}

Nuclear reactor safety has drawn attention right from the time Chicago Pile-1 designed by Enrico Fermi went critical in 1942. For example, the 'SCRAM' function or feature for quick reactor 


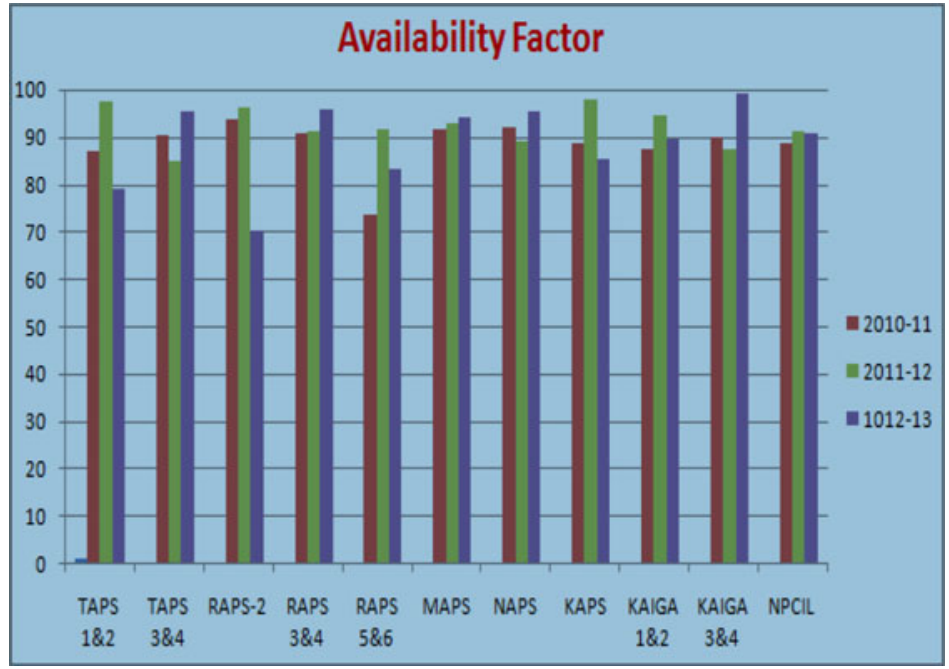

Figure 4. Availability factors of Indian NPPs.

shutdown on any unacceptable condition was considered by Fermi in his first attempt of establishing a chain reaction. The genesis of Nuclear Reactor safety in NPP (Bhardwaj 2013) has the objective that fuel should be cooled at all given times and the radioactive fission products and minor actinides are confined within the plant. Safety encompasses all the stages of the nuclear power plant execution from siting, design, construction, testing, commissioning and operation to eventual decommissioning. Defense-in-depth concept has evolved over the years to assure safety of a NPP. Each experience, national and international is reviewed and safety provisions revisited and improved upon, if required. The subject of safety is ever-evolving. The performance of Indian nuclear power reactors in terms of safety has been excellent, with over 360 reactor years

\section{Gestation period for Nuclear Power Plants From first pour of concrete to commercial operation Grid connection from 2002}

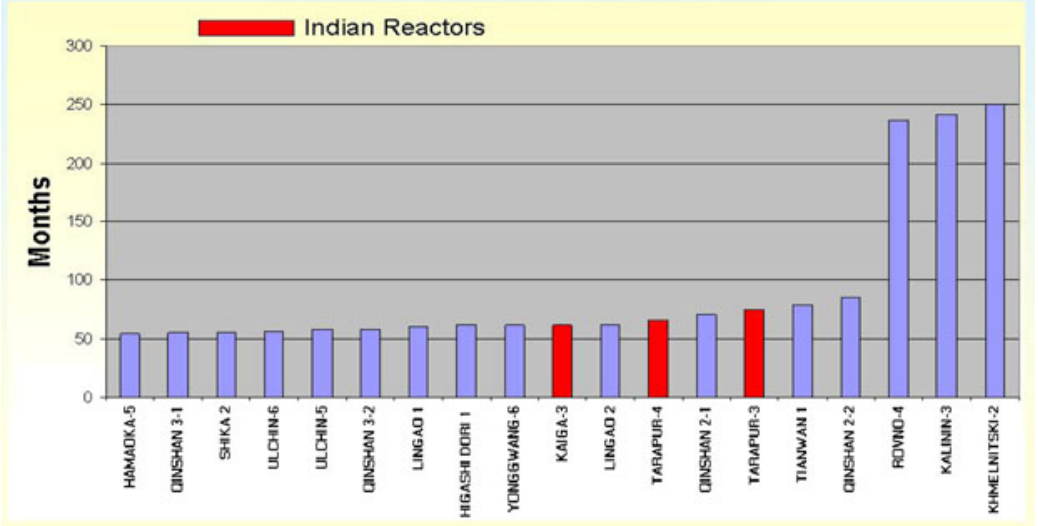

Figure 5. Construction performance. 
of safe, accident-free operation. The releases to the environment have been a small fraction of the limit prescribed by the Atomic Energy Regulatory Board (AERB). The papers in this volume elaborately cover current safety design practices and the advances being made in Indian Nuclear power programme (Joshi et al 2013; Vijayan et al 2013; Vaze 2013).

There is a strong safety culture prevalent in the organizations of DAE. Progressive upgradation of technologies through in-house safety reviews, continued priority support from R\&D institutions of Department of Atomic Energy (DAE) on safety research, training, qualification, quality assurance and environmental protection are the highlights to assure safety.

Independent multi-tier safety reviews and the detailed process of authorizations for construction/commissioning of new plants and periodic safety reviews of operating plants by Atomic Energy Regulatory Board (AERB) add value and maintain vigil on all aspects of safety. The regulatory mechanism is India is robust. The Atomic Energy Regulatory Board (AERB), an institution independent of the DAE, monitors and enforces safety in Indian nuclear power plants (Bajaj 2013). While AERB has in place a multitier elaborate review and authorization process for Nuclear, Industrial and Radiation Safety in Indian NPPs, following salient additional review mechanisms are also implemented:

- Review by Station Operation Review Committee (SORC) comprising of senior experienced personnel in each stations headed by Station Director, reviews the operation, adherence to technical specifications radiological aspects and recommend the improvements.

- Periodic Internal Review for Safety assurance are conducted by a team of officials independent to executing personnel. The status of implementation of recommendations is reviewed and monitored by Station Director/Project Director. Corporate Reviews conducted by a corporate Review team comprising of the senior nuclear professionals from Corporate Office, plants other than the reviewed plant. The Corporate team reviews all functional areas, cross functional areas and safety culture, in specific.

- World Association of Nuclear Operators (WANO), an international non-governmental organization conducts reviews by pooling the nuclear technology experts across the globe. Such reviews volunteered by the utility are also conducted once in five years for each plant. All Indian NPPs are being periodically reviewed by this process.

- International Atomic Energy Agency (IAEA) also conducts safety reviews through its Operational Safety Review Team (OSART) programme. In OSART missions, the IAEA coordinates internationally-based teams of experts who conduct reviews of operational safety performance at nuclear power plants. India invited this group for review of safety during year 2012 at RAPS 3\&4 (IAEA 2012).

Industrial Safety in construction plant is of high significance due to the involvement of low educated unskilled workforce, which is large in number, employed for a specific purpose and time duration. Therefore, to ensure effective management of Industrial Safety in Plants, a dedicated and independent Industrial Safety Section is in place. This group is headed by a senior and qualified safety professional who directly reports to respective Station/Project Head, to ensure safety is given the top most priority. The Safety Head and Safety Officers have been empowered to stop the work, in cases of hazardous work environment or inadequacy in procedures for protection.

\subsection{Operating experience feedback for enhancing safety-aftermath of Fukushima}

Use of operating experience feedback for enhancing safety of NPPs has all along been accorded high importance in India. Lessons learned from Three Mile Island and Chernobyl accidents 
and from several other operational incidents in NPPs in India and abroad, as also from new knowledge gained through research have been appropriately used for design and procedural improvements to enhance safety of our NPPs from time to time. The exercise of reviewing the safety of Indian NPPs in the light of the Fukushima accident by NPCIL and AERB has been in this context (Report of AERB Committee 2011; Review of Indian NPPs 2011).

The prime reason for the Fukushima Nuclear Power Plant incident at Japan in March 2011 was the severe earthquake and the ensuing tsunami of a large height. The catastrophic earthquake resulted in an automatic plant shutdown. All the instrumentation/equipment in the plant worked as designed, without any loss of function. Post shutdown, cooling of the fuel inside the reactor started as intended in the design even when offsite power supply was lost due to the earthquake. However, after about half an hour, tsunami of a height of $14-15 \mathrm{~m}$, as against the designed height of $5.7 \mathrm{~m}$ disrupted all the power supplies including the diesel generators at the plant, impairing the core cooling which resulted in the incident.

Nevertheless, there were no deaths reported due to radiation. Nuclear plants in the vicinity (Onagawa, Fukushima Daiini and Tokai) reported no nuclear damage due to the earthquake or tsunami as minimum power supply continued in spite of the natural calamity. This clearly emphasizes a nuclear plant's ability to withstand natural disasters. Can Fukushima happen in India? As against Japan's NPPs, India's NPPs are in relatively earthquake stable continental region (low to moderate earthquake zone). Nevertheless, the NPPs in India are designed conservatively considering the local earthquake and the postulated flood levels. The water reservoirs can cater to the cooling requirement in case of emergency for a period of 7 days or more; in some cases, even up to 30 days. NPPs at coastal sites (Kalpakkam, Kudankulam and Tarapur) are also above the possible tsunami level in their respective zones. The safety of plants has been reviewed afresh after the Fukushima incident and additional strengths in safety being executed (Review of Indian NPPs 2011). These comprise of portable electrical equipment and diesel driven pumps enabling hook-up to the reactor systems.

PHWRs form the back bone of the current Indian nuclear power programme. In this design, cooling of the reactor core, with the plant in hot shut down state, is achieved by natural convection flow of reactor coolant through steam generators. With the design provision for charging water to the secondary side of the steam generators using diesel engine driven pumps, this mode of core cooling can be maintained even under extended unavailability of electricity from external grid as well as plant's own emergency diesel generators, a situation called Station Black Out (SBO). The efficacy of this design feature got amply demonstrated during the 17 hours long SBO caused by the turbine hall fire incident at Narora unit-1 in 1993 when reactor core cooling could be successfully maintained. Similarly MAPS, nuclear power plant at Kalpakkam withstood the giant tsunami waves on 26th December, 2004. The plant shut down automatically as the water level rose in the intake pump house. There was no release of radioactivity. The reactor was restarted after a regulatory review on 1 January 2005, six days after the catastrophic waves struck India's east coast. Nevertheless, understanding of natural hazards is ever-evolving and due conservatism is addressed in assuring nuclear safety (AERB Committee 2011; Review of Indian NPPs 2011; Kakodkar and Singh 2013).

\subsection{Fuel development}

The first stage of the programme consists of uranium-fuelled reactors. There is continuous design and development of fuel for various reactors of this stage. For example, $6 \times 6,7 \times 7$ fuel configurations for BWRs at Tarapur and 19, 22, 37 fuel rod bundles for PHWRs have been developed. 
The fuel design, fabrication and quality control procedures have been improved from time to time to meet enhanced fuel performance requirements at par with international benchmark.

Plutonium and thorium fuels will form part of second and third stage programme. Work on establishing science and technology of such fuel types has been a prominent part of fuel related R\&D activities. Based on development of MOX fuel fabrication for experimental irradiation in research reactors an Industrial scale MOX fabrication plant was set-up at Tarapur. Several lead MOX fuel assemblies were irradiated in TAPS-1 and TAPS-2 (BWRs) successfully to the design burn-up. Development of high burn-up fuels for use in PHWRs was also done by experimental 50 MOX fuel bundles fabricated for PHWRs. All the MOX bundles irradiated in PHWR have seen peak burn up $>20,000 \mathrm{MWd} / \mathrm{t}$. These irradiations demonstrated capability in reactor physics, engineering design, fabrication, quality control and safe operation of plutonium-bearing fuel. Similarly, thorium oxide fuel has been used in many PHWR plants during initial fuel loading to limit excess reactivity as well as use the opportunity for demonstrating the science and technology capability in thorium fuel (Balakrishnan and Kakodkar 1994).

PHWRs use natural uranium as fuel. However, as the country goes for LWRs, it is possible to use reprocessed uranium obtained from reprocessing the spent fuel of LWRs in PHWRs. The LWRs use enriched uranium containing around $4 \%{ }_{235} \mathrm{U}$ for fuel loading, which after reactor use still has left over uranium slightly higher in enrichment (around $1 \%{ }_{235} \mathrm{U}$ ) than natural uranium. With the future objective of using such reprocessed uranium with concentration marginally higher than natural uranium from LWRs in PHWRs requisite reactor physics studies, fuel design, safety studies were taken up. About fifty fuel bundles with $0.9 \%$ enriched fuel bundles were fabricated and subjected to in reactor tests for full life and operating conditions in a PHWR. The results of this work have been successful and this feature is planned to be implemented in Indian PHWRs as part of the induction of LWRs in the first stage programme. This is a unique way to maximize the use of mined uranium (Prasad et al 2006).

\subsection{Aging management}

Managing of aging nuclear power plants means ensuring the availability of required safety functions throughout the life of the plant, taking into account of changes that occur with time and use. Nuclear power plants experience two kinds of time dependent changes:

(i) Physical ageing of Systems Structures and Components (SSCs), which results in degradation, i.e., gradual deterioration in their physical characteristics; (ii) Obsolescence of SSCs, i.e., their becoming out of date in comparison.

Aging management applies to both above time dependent changes and in particular applies to Systems Structures and Components of a NPP that can have an adverse effect on the safe operation of the NPP. Thus the periodic health assessment and ageing management is an integral part of the nuclear power technology to assure the safety and reliability in all phases of nuclear power, encompassing design, construction, commissioning, operation and waste management. A detailed aging management program for Indian NPPs is drawn and is rigorously followed (Bhardwaj 2004). The inspections or a replacement within the calandria/reactor vessel, which is radioactive and generally inaccessible for direct working, needs special toolings. Amongst other generic aging management issues which are common for most types of NPPs, usually with regard to electrical or instrumentation systems, PHWRs need specific attention to aging of Pressure tubes in the reactor. These pressure tubes contain fuel and permit high pressure, high temperature coolant to flow over the fuel for heat removal. Special remotely operable tools have been developed by BARC, NPCIL and other institutions of the DAE. Some of them are: BARC Reactor Coolant Inspection System (BARCIS), Non-Intrusive Vibration 
Diagnostic Technique (NIDVT), Integrated Garter Spring Repositioning System (INGRES), Sliver Sample Scraping Tool (SSST), Hydraulic Remote Inside Diameter Measuring (HYRIM) Tool and several other specialized cameras, manipulators, welding tools, etc. (Jain 2010; Puri et al 2004; http://barc.gov.in/rddg/rddg/mod_rddgact/mainprog/agemanag.htm). These tools have been extensively deployed in operating reactors to monitor life limiting phenomenon and assure safety till the pressure tubes are due for replacement (Singh et al 2007; Sinha and Sinha 2013; Northwood and Kosasih 1983). The replacement of Pressure tubes is a major life extension exercise in a PHWR and the opportunity is used for upgrading safety and implementing overall renovation of the plant to overcome obsolescence.

The pressure tubes were initially constructed of Zircaloy-2 material in PHWRs (Suri), and the health assessment studies carried out during operation, revealed that their life span was limited due to alteration in the material properties under exposure to intense radiation, high temperature and pressure and a corrosive environment. The material degradation mechanism in Zircaloy-2 coolant channels was essentially an accelerated corrosion after about ten to twelve years of operation and increase in uptake of hydrogen by zircaloy material. The new material developed is Zirconium-2.5\% and Niobium (Suri 2013; Singh 2002) —a better material with no accelerated corrosion domain and lower hydrogen pickup. The coolant tubes of Zircaloy-2 installed originally in six of the operating nuclear power reactors and have been replaced by $\mathrm{Zr} 2.5 \% \mathrm{Nb}$ alloy pressure tubes at the end of their life by carrying out successfully en-masse coolant channel replacement (EMCCR) using indigenous technology.

Similarly the feeder pipes, made of carbon steel, are an important component of the coolant system in a PHWR. Feeder thinning on account of flow-assisted corrosion (FAC) was first noticed in 1995 in Canadian PHWRs. The studies on FAC mechanism revealed that higher flow velocity at the bend portion of feeders along with the coolant $\mathrm{pH}$ of more than 10.5 contributed to accelerated FAC. The health assessment of feeders in Indian nuclear reactors showed lower FAC than Canadian PHWRs. This was attributed to maintaining of primary coolant $\mathrm{pH}$ in a narrow band of 10.2 to 10.4. However, to extend the life of the Indian PHWRs and it was decided to take up the en-masse feeder replacement whenever opportunity arises, normally along with EMCCR. Improvements have been made in material of feeders for new reactors and improved chemistry control is being exercised for extending life of these feeders.

The health assessment of BWRs at Tarapur has been carried out using the latest and advanced techniques. Based on these studies, the plant life has been extended by replacing the important equipment/components. In addition to this, safety upgradation of the units has also been completed successfully. The Tarapur units after renovation and modernization are operating with availability Factors near $100 \%$ and have completed 44 years of operation.

\subsection{Maintenance challenges overcome}

There also have been special repair/maintenance challenges necessitating work to be taken up in the high radiation field areas, which have been successfully addressed by developing appropriate remote tools and methodologies for executing the jobs, in mission mode. Major such missions undertaken were (Jain 2010):

- Repair of RAPS-1 End-shield

- Introduction of Spargers in MAPS-1\&2

- Repair in Kaiga-3 End-shield 
Such unusual activities required analysis, evaluation of design alternatives, analytical/ experimental work, development of remotely operated automatic tools and their manipulators, demonstration on mockups, and executing on the reactor. These were highly specialized and complex job and were successfully taken up in association with industry.

\subsection{First stage achievement}

The execution of Stage-1 programme so far with 18 Pressurized Heavy Water Reactors (PHWRs) based on natural uranium in operation and more in construction has demonstrated the maturity achieved in the research, design, development and successful commercial deployment of nuclear technology in the country. The present and future R\&D being carried out and planned for Fast Breeder Reactors of the second stage and use of thorium in third stage of the programme would similarly be able to meet long term energy requirement of the country.

\section{Second stage}

As already covered above, FBR programme was started by constructing a loop type Fast Breeder Test Reactor (FBTR), which is in operation since 1985. With the PHWR programme well on its growth path and having provided desired spent fuel quantities bearing Plutonium, expertise gained in FBR Technology through successful operation of FBTR over 27 years, India is now on a robust path for moving into Second Stage of the programme. Thus construction of a Prototype Fast Breeder Reactor (PFBR) based power unit of 500 MWe capacity was launched in October 2003. PFBR, a pool type mixed $\mathrm{Pu}-\mathrm{U}$ oxide(MOX) fuelled Fast Reactor, is the outcome of design and development work on all related elements of science and technology performed at Indira Gandhi Centre for Atomic Research, Kalpakkam along with other DAE units, National Labs and academic institutions. The stage-wise commissioning of this unit, which is first of its kind in the country will involve many tests to provide valuable validation on the science and technology aspects. Following these validations and a minimum operational experience, additional units of 500 MWe, MOX fuel-based FBRs could be taken up.

MOX-based fuel cycle has been adopted based on national and international experience on oxide fuels in PHWRs and LWRs. However, breeding gain in fuel cycle using MOX fuel in FBRs is rather limited. Thus after gaining experience in operating FBRs with such proven MOX fuels it is planned to deploy metal fuelled FBRs (1000 MWe capacity) which offer promise of high breeding ratio. The development work for metallic power reactor fuel has been initiated. The nuclear power capacity thereafter is expected to grow relatively rapidly. Large scale deployment, of FBR technology particularly to take advantage of optimum breeding- development work on additional challenges in science, design, safety and technology, especially in fuel cycle and core structural materials has been taken up and is being conducted in time bound manner. The details on second stage of the programme are elaborated in a separate paper in this issue (Chetal and Chellapandi 2013).

\section{Third stage}

Development of technologies pertaining to utilization of thorium is important for long term energy security of the country. Thorium offers number of physics and engineering advantages for 
use in reactors. Waste products on irradiation of thorium contain almost no long-lived radioactive minor actinides compared to those from use of uranium or plutonium fuels. However, the production of ${ }_{233} \mathrm{U}$ through the irradiation of ${ }_{232} \mathrm{Th}$ invariably produces small amounts of ${ }_{232} \mathrm{U}$. The decay chain of ${ }_{232} \mathrm{U}$ yields strong gamma radiation emitters. This makes handling of ${ }_{233} \mathrm{U}-$ 232 Th more complex. This is one of the major challenges in R\&D to develop processes of fuel cycle requiring well-engineered handling systems to facilitate commercial scale deployment of such systems.

Considerable thorium irradiation experience has been acquired in research reactors and thorium has been introduced in PHWRs in a limited way (Kannan and Krishnani 2013). The third stage technology for utilization of Thorium 232 has been demonstrated in small measures. For example, the KAMINI reactor, in IGCAR, the only currently operating reactor which uses ${ }_{233} \mathrm{U}$ as fuel. This fuel was bred, processed and fabricated indigenously. Efforts are currently on to enlarge that experience to a bigger scale.

The third stage of programme is aimed to meet the following goals:

- Utilisation of thorium as fuel on a commercial scale.

- Sustaining a large nuclear power capacity developed in second stage for a very long period, till thorium is available.

- Achieving good economic performance as compared to alternate options for energy generation.

- Attaining higher levels of transparent safety, through optimal utilization of inherent and passive safety features.

- Utilizing the proliferation resistant potential of thorium fuel cycle to the full extent.

Further development on advanced thorium reactors to ultimately use thorium resources on a commercial basis is in progress. Thorium is not fissile material. Thorium will be introduced in blanket locations on the periphery of FBR reactor cores some time in second stage programme after sufficient nuclear capacity is built up in the country through Fast Breeder Reactors. Thus generation of ${ }_{233} \mathrm{U}$ will be initiated in the second stage of the programme. Fast Reactors can gradually begin to use ${ }_{233} \mathrm{U}-232 \mathrm{Th}$ fuels in the reactor core itself thus making transition to third stage of the programme. Considering the sequential nature of the programme, and the lead time involved at each stage, it is important to realize that direct large scale thorium utilization will take time. In addition to use of thorium in fast reactors, various other reactor designs are being developed for demonstrating use of thorium. The objective of these reactor systems is briefly covered below.

The frontline technology being developed amongst these is the Advanced Heavy Water Reactor (AHWR). The AHWR is an innovative concept, which is a bridge between the first and third stage systems. It uses light water as coolant and heavy water as moderator. It can be fuelled to suit a variety of fuel cycles like a mixture of enriched uranium and thorium-based fuel or Plutonium and thorium, with a sizeable amount of power coming from Thorium. This reactor also has been designed to use a number of advanced passive safety features making it the next generation safe plant. The Advanced Heavy Water Reactor (AHWR) project, discussed separately in this volume (Vijayan et al 2013; Vaze 2013), provides a focal point for a time bound high intensity development in the efficient utilisation of thorium.

Another aim of third stage programme is to extend the use of nuclear power to nonelectrical applications in a big way, in particular for desalination and high temperature processing applications, including those for generation of hydrogen or non-fossil fluid fuels. 
To meet these objectives in medium as well as long term time frames, keeping the current international trends in nuclear technology in view, the third stage of Indian nuclear power programmes has following product development plan:

- Advanced Heavy Water Reactor (AHWR).

- High temperature reactor-based power packs for high temperature process heat and hydrogen fuel production.

- Accelerator driven fertile converters, with fast sub-critical reactor, minor actinide burner.

- Molten Salt Reactors including breeders for generating electrical power, high temperature process heat and transmutation of minor actinides.

- Core together with a mainly thorium-fuelled thermal core somewhat similar to that present in AHWR.

In the Accelerator Driven System (ADS), high-energy proton beam generates neutrons directly through spallation reaction in a non-fertile/non-fissile element like lead. A subcritical blanket with lesser fissile requirement will further amplify this external neutron source as well as energy. Development of such a system offers the promise of shorter doubling time with ThoriumUranium 233 systems, transmutation of long lived actinides and fission products and robustness to approach towards realization of the objective of large scale thorium utilization. Transmutation or incineration of minor actinides is also possible in Fast Reactors, molten salt breeder reactors and is part of future development objective of second stage.

India is also a partner in the international experimental initiative on harnessing fusion power for the future, the International Thermonuclear Experimental Reactor (ITER) project. India is supplying several components for the experimental reactor.

\section{Waste management}

The technology for dealing with low and intermediate level radioactive wastes from nuclear power plants has been well-established and the processes for treatment and disposal are in practice for the past several decades meeting the regulatory requirements. The wastes generated during operation of nuclear power plants are of a very low activity level. They are managed at the plant site itself by appropriate methods. The combustible wastes are incinerated. The solid/liquid wastes are concentrated and immobilized in cement of polymer matrices and stored at the plant site in near surface storage facilities. The gaseous wastes (exhaust from ventilation of plant buildings) is filtered through High Efficiency Particulate filters for any particulate matter and discharged through a high stack.

Closed fuel cycle option followed in India is beneficial from radioactive waste management angle in terms of reducing considerably the volume of high level waste to be handled. High level wastes are generated during reprocessing of fuel. The quantity of such high level wastes to be managed is relatively small. For example, the high level waste generated by a $1000 \mathrm{MWe}$ station is of the order of one ton per year. India has developed the technologies in this regard which is immobilization in inert glass matrix by a process of vitrification and such waste immobilization plants are in operation. After intermediate storage in specially designed facility for the required period, ultimate disposal of immobilized waste will be in a repository. R\&D work is in progress on the ultimate repository. As the quantity of high level waste generated in a closed nuclear fuel cycle is very small, accumulation of sufficient volume for a repository will take time. Thus there is adequate time available to choose the best technological option for ultimate disposal in a repository based on further developments in this field. Sustainability of nuclear power depends on 
management of long lived wastes. Thus, in addition to conditioning as well as disposal, including deep geological repository development in partitioning and transmutation of waste are also part of technology development plan as mentioned above. The subject of waste management is separately detailed in this issue (Wattal 2013).

\section{Conclusions and road ahead}

Nuclear power has an important role to play in the country's energy scene, complementing generation from other sources in the near term and providing energy security in the long term while abating climate change.

Indian Nuclear power program, visualized by Dr. Bhabha in early fifties is on course and is being developed and successfully deployed with indigenous efforts, placing the country in elite club of countries possessing advanced nuclear technology. The evolution and development of commercial nuclear technology in the country has passed through several technological challenges. While developing and implementing the nuclear power program, the Indian industry's capability in manufacturing and supply of high precision and specialized equipment has also been developed comparable to international standards. The nuclear power has come of age with comprehensive capabilities in all aspects of nuclear power and is poised for a large expansion program. The challenge is to develop and commercially deploy technologies of Fast Breeder Reactors in a big way to increase the installed nuclear power capacity in the country to a desired level followed by large scale utilization of thorium to sustain this capacity for a very prolonged period thus ensure long term energy security. The fruition of international cooperation will in addition open up plethora of opportunities in import and export of nuclear goods, equipment and services. The Indian nuclear power sector and industry needs to evolve faster to meet the associated challenges.

\section{References}

Bajaj S S 2013 Regulatory practices for nuclear power plants in India

Bajaj S S and Gore A R 2006 The Indian PHWR, Nucl. Eng. Des. 236(7-8): 701-722

Balakrishnan K and Kakodkar A 1994 Optimization of the initial fuel loading of the Indian PHWR with thorium bundles for achieving full power, Ann. Nucl. Energy 21(1): 1-9

Bhardwaj S A 2004 Ageing management programme and in-service inspection in Indian PHWRs, http://pbadupws.nrc.gov/docs/ML0425/ML042540325.pdf

Bhardwaj S A 2006 The future 700 MWe pressurized heavy water reactor, Nuclear Eng. Des. 236(7-8): 861-871

Bhardwaj S A 2013 Nuclear reactor safety, India's nuclear energy programme future plans- prospects and concerns, R Rajaraman (ed.) Academic Foundation, INSA, New Delhi

Chetal S C and Chellapandi P 2013 Indian Fast Reactor Technology: Current Status and Future Programme

Energy Statistics 2012 Central Statistics Office, Ministry of Statistics and Programme Implementation, Government of India

Grover R B and Puri R R 2013 Development of human resources for Indian nuclear power programme

Human Development Report 2007 Access to Energy and Human Development, UNDP

IAEA 2012 Leads Operational Safety Mission to Rajasthan Atomic Power Station 3 and 4, IAEA Press Release 2012/27, 14 November 2012

Integrated Energy Policy 2006 Report of the Expert Committee, Planning Commission, Government of India 
Jain S K 2010 Nuclear Power in India - Past, present and future, http://www.npcil.nic.in/pdf/CMD_ paper_07dec2010.pdf

Joshi J B, Nayak A K, Singhal M and Mukhopadhaya D 2013 Core Safety of Indian NPPs under Extreme Conditions

Kakodkar A and Singh R K 2013 Integrated safety assessment of Indian nuclear power plants for extreme events: Reducing impact on public mind

Kannan U and Krishnani P D 2013 Energy from thorium - An Indian perspective

Leung Chi Seng 2005 How electricity consumption affects social and economic development by comparing low, medium and high human development countries, http://www.geni.org/globalenergy/ issues/global/qualityoflife/HDI-vs-Electricity-Consumption-2005-07-18.pdf

Load Generation Balance Report 2013-14 Central Electricity Authority, Ministry of Power, Government of India

Northwood D O and Kosasih U 1983 Hydrides and delayed hydrogen cracking in zirconiu and its alloys, Int. Metals Rev. 28(2): 92

Nuclear Power and sustainable development IAEA 2000 Publication no. 02-01574/FS Series 3/01/E/Rev. 1

Pachauri R K and Reisinger A (eds) Climate Change 2007: Synthesis Report, Core writing team, IPCC, Geneva, Switzerland

Parthasarthy K 2010 www.rpe.org.in/text.asp?2010/33/3/88/86261, Dr A K Ganguly Memorial Oration

Prasad P N, Rahul Mani Tripathi, Dwivedi K P, Kumar A N, Parikh M V 2006 Fuel design, development and performance experience in Indian PHWRs, http://www.iaea.org/OurWork/ST/NE/NESeries/ WorkingMaterials/PHWR-fuel-WM.pdf

Puri R K, Haruray A K, Padmanabhan M, Bapat H M and Manjit Singh 2004 Indigenous development of miniature underwater radiation resistant Cctv Camera for remotised inspection of coolant channels of PHWRs. BARC News Letter

Regulaton Framework: Early Years 2008 Atomic energy regulatory board 25 years of safety regulation. http://www.aerb.gov.in/AERBPortal/pages/English/t/sj/book/chapter1.pdf

Report of AERB Committee to Review Safety of Indian Nuclear Power Plants against External Events of Natural Origin, August 31, 2011, http://www.aerb.gov.in/AERBPortal

Review of Indian NPPs -Post Fukushima Event 2011 http://www.npcil.nic.in

Saga of Atomic Energy in India 2005 http://dae.nic.in

Singh R N 2002 "Flow behavior and hydrogen embrittlement of Zr-2.5 wt. \% Nb pressure tube alloy" $\mathrm{Ph}$. D. Thesis, IIT Bombay, India

Singh R N, Chaterjee S and Banerjee S 2007 PHWR Coolant channel safety issues - A metallurgical perspective, Proc. of 1st National Conf. on 'Nuclear Reactor Technology - NRT-1' Nuclear Reactor Safety

Sinha S K and Sinha R K 2013 Corrosion and Hydriding Model for Zircaloy-2 Pressure tubes of Indian PHWRs, http://www.astm.org/COMMIT/B10_Zirc_Presentations/Presentations/4.4_sinha_ corrosion_and_hydriding_model.pdf

Suri A K 2013 Material development for India's nuclear power programme

Stern N 2007 The Economics of Climate Change, The Stern Review

Vijayan P K, Kamble M T, Nayak A K, Vaze K K and Sinha R K 2013 No emergency planning in public domain - the way ahead for nuclear power plants

Vaze K K 2013 Structural integrity aspects of reactor safety

Wattal P K 2013 Indian program on radioactive waste management 